\title{
A Novel Fusion Protein, AChR-Fc, Ameliorates Myasthenia Gravis by Neutralizing Antiacetylcholine Receptor Antibodies and Suppressing Acetylcholine Receptor-Reactive B Cells
}

\author{
Masayuki Homma $^{1}$ - Akiyuki Uzawa ${ }^{2}$ Hitoshi Tanaka ${ }^{1}$ - Naoki Kawaguchi ${ }^{2}$. \\ Tetsuya Kanai ${ }^{2}$ - Kenji Nakajima ${ }^{1}$ • Masakuni Narita ${ }^{1}$ - Yukio Hara ${ }^{1}$. \\ Hideya Maruyama ${ }^{1}$ - Yasumasa Ogawa ${ }^{1} \cdot$ Keiichi Himuro $^{2} \cdot$ Satoshi Kuwabara $^{2}$
}

Published online: 27 September 2016

(C) The American Society for Experimental NeuroTherapeutics, Inc. 2016

\section{Introduction}

Myasthenia gravis $(\mathrm{MG})$ is a disease caused by autoantibodies against the nicotinic acetylcholine receptor (AChR) [1], or muscle-specific kinase [2], at the neuromuscular junction. In recent years, autoantibodies, recognizing low-density lipoprotein receptor-related protein 4 , have also been considered to be a cause of MG [3]. Anti-AChR antibodies are observed in approximately $80 \%$ of patients with MG [4,5], and prevent AChR from binding to acetylcholine, which otherwise plays a crucial role in neuromuscular signaling. These autoantibodies also promote degradation of the receptor and mediate activation of complement that leads to destruction of the receptor [6].

Steroids, immunosuppressants, thymectomy, and/or cholinesterase inhibitors are used as conventional treatments for MG. Plasmapheresis and high-dose intravenous immunoglobulin are treatment options intended to eliminate autoantibodies in patients with MG; however, these options are expected to have a temporary effect, are time-consuming, and are costintensive for patients. Treatment with steroids and immunosuppressants carries the risk of several side effects. Therefore, given the current state of MG treatment, there is a need to develop new therapeutic options for this disease. In the present study, we created a novel fusion protein (AChR-Fc) that can specifically neutralize anti-AChR antibodies and inhibit their production by $\mathrm{B}$ cells, without suppressing overall immune function. AChR-Fc is a fusion protein of $\mathrm{Fc}$ and $\mathrm{AChR}(\alpha 1$ subunit extracellular domain); therefore, it is expected to have neutralization activity and cytotoxicity for autoantibodyproducing $\mathrm{B}$ cells. The potential of AChR-Fc has already been reported by Chang et al. [7]. In the present study, we developed a construct with AChR at the N-terminal side, which was 
different from the construct examined by Chang et al. [7], and analyzed its effects in vitro and in vivo. This paper is the next step of previous report, and we report promising results using our construct, AChR-Fc, in an experimental rat model of MG.

\section{Materials and Methods}

\section{Ethical Statement}

All experiments were performed in accordance with relevant guidelines and regulations.

Animal experiments were conducted in reference to the Act on Welfare and Management of Animals in Japan and Basic Guidelines for Proper Conduct of Animal Testing and Related Activities in the Research Institutions under the Jurisdiction of the Ministry of Health, Labour, and Welfare. All patients provided written informed consent for their participation in the present study. Ethical approval was granted by the ethics committee of the Chiba University School of Medicine, Chiba, Japan and the ethics committee of the Nihon Pharmaceutical Co., Ltd. All patients gave written informed consent for their participation.

\section{Construction and Preparation of AChR-Fc}

We designed a peptide sequence fusing the extracellular domain of human AChR $\alpha 1$ subunit (H $\alpha 1-210$, Swiss-Prot ID: P02708-2) to the human IgG1 heavy chain (Swiss-Prot ID: $\mathrm{P} 01857)$ constant region using the linker amino acid sequence, $\mathrm{P}(\mathrm{GGGGS})_{3}$. A recombinant expression plasmid was created, incorporating the above sequence, and transfection into Chinese hamster ovary-K1 cells was performed. Stable clones, expressing AChR-Fc, were obtained after selection, and these cells were cultured.

Expressed AChR-Fc was affinity purified using protein A column chromatography (MabSelect SuRe; GE Healthcare, Little Chalfont, UK). Subsequently, further purification was performed by anion exchange column chromatography (Fractogel ${ }^{\circledR}$ TMAE; Merck Millipore, Billerica, MA, USA) and hydrophobic interaction column chromatography [phenyl (high); GE Healthcare]. The purified protein was dialyzed against experimental buffers.

\section{Preparation of $\mathbf{m A b 3 5}$}

Rat anti-AChR antibody mAb35 was prepared by using rat anti-AChR $\alpha 1$ subunit antibody-producing hybridoma cells (ATCC; TIB-175). TIB-175 cells were cultured with Hybridoma-SFM medium (Life Technologies, Carlsbad, CA, USA). The supernatant was purified using protein A column chromatography (MabSelect SuRe; GE healthcare).

\section{Analysis of Affinity Using Surface Plasmon Resonance}

The affinity and binding capacity of AChR-Fc to mAb35 was measured at $25{ }^{\circ} \mathrm{C}$ using a BIACORE2000 (GE Healthcare). AChR-Fc was diluted with acetate buffer (pH 5.0) to a concentration of $20 \mu \mathrm{g} / \mathrm{ml}$, and fixed on a sensor chip CM5 by amine coupling (approximately 1000 RU). The mAb35 solutions (6.25-200 nM) were reacted at a flow rate of $20 \mu \mathrm{l} / \mathrm{min}$. The obtained sensorgram was analyzed by the global fitting method (1:1 binding model) using BIA evaluation software.

\section{IgG and Peripheral Blood Mononuclear Cell Fractions Obtained From Patients With MG}

The IgG and peripheral blood mononuclear cell (PBMC) fractions were prepared from the peripheral blood of patients with MG treated at Chiba University, and from healthy volunteers. The severity of the disease was classified according to the Myasthenia Gravis Foundation of America Clinical Classification at sampling [8]. Blood samples were collected and then diluted with an equal volume of physiological saline. The diluted blood samples were layered over Ficoll solution (Lymphoprep ${ }^{\mathrm{TM}}$; AxisShield PoC AS, Dundee, UK), and the plasma and PMBC fractions were separated by centrifugation.

The IgG fraction was obtained by directly applying the plasma fraction in protein A column chromatography (HiTrap protein A; GE Healthcare). PBMCs were cryopreserved in liquid nitrogen. At the time of the experiment, the fraction was suspended in RPMI1640 (Gibco, Carlsbad, CA, UK) with $10 \%$ fetal bovine serum, $0.21 \%$ sodium bicarbonate solution (wt/vol), $2 \mathrm{mM} \mathrm{L-}$ glutamine (Gibco), and antibiotics. Hereafter, this medium was used for culture of PBMC.

\section{Evaluation of the Binding Between AChR-Fc and Patients' IgG}

The binding of AChR-Fc to patient IgG was evaluated by enzyme-linked immunosorbent assay (ELISA). IgG fractions at different concentrations were immobilized $(0.24 \mu \mathrm{g} / \mathrm{ml}$ $4.0 \mathrm{mg} / \mathrm{ml}, 4^{\circ} \mathrm{C}$, overnight) and a specific quantity (saturated) of AChR-Fc was added for the reaction $\left(10 \mu \mathrm{g} / \mathrm{ml}, 37^{\circ} \mathrm{C}, 2 \mathrm{~h}\right)$. Subsequently, samples were reacted with biotinylated $\alpha$-bungarotoxin $\left(5 \mu \mathrm{g} / \mathrm{ml}, 37{ }^{\circ} \mathrm{C}, 1 \mathrm{~h}\right.$; Molecular Probes, Eugene, OR, USA) and with streptavidin-horseradish peroxidase (GE Healthcare). After development with 3, 3', 5, 5'-tetramethylbenzidine substrate (Thermo Fisher Scientific, Waltham, MA, USA), the absorbance of samples was measured at $450 \mathrm{~nm}$. 


\section{Measurement of Anti-AChR Antibody Titers}

The antibody titers against AChR were measured using an Acetylcholine Receptor Autoantibody RIA Kit (RSR Ltd, Cardiff, UK), according to the manufacturer's instructions.

\section{Confirmation of Binding to Hybridoma TIB-175 Cells}

TIB-175 cells cultured in Hybridoma-SFM medium were washed with Hanks' balanced salt solution /bovine serum albumin and incubated with AChR-Fc $(100 \mu \mathrm{g} / \mathrm{ml})$; detection was performed using phycoerythrin-labeled human IgG antibody (Jackson ImmunoResearch Laboratories, West Grove, PA, USA) and flow cytometry via a Cytomics FC500 flow cytometer (Beckman-Coulter, Brea, CA, USA).

\section{Measurement of Cellular Cytotoxicity}

NK92 human natural killer cells (ATCC: CRL-2407) were cultured with RPMI1640 (Gibco), $12.5 \%$ horse serum, $12.5 \%$ fetal bovine serum, and $150 \mathrm{U} / \mathrm{ml}$ recombinant interleukin-2. Cultured TIB-175 cells were centrifuged and washed with bovine serum albumin/Hanks' balanced salt solution. After adding the fluorescent reagent Calcein-AM (Invitrogen, Carlsbad, CA, USA), the samples were incubated at a temperature of $37^{\circ} \mathrm{C}$ for $30 \mathrm{~min}$ to increase the absorption of Calcein-AM. TIB-175 cells labeled with Calcein-AM were seeded in a 96-well plate at 1000 cells/well. Different concentrations of AChR-Fc and NK92 cells (25,000 cells/well) were added to the plate and incubated at a temperature of $37^{\circ} \mathrm{C}$ for $4 \mathrm{~h}$. After incubation, the cells were precipitated by centrifugation, and the fluorescence of the supernatant was measured $($ Ex. $=485 \mathrm{~nm}$, Em. $=540 \mathrm{~nm})$. In addition, phosphate buffered saline (PBS; mock), medium only (control), and etanercept (a fusion protein in the tumor necrosis factor- $\alpha$ receptor and the Fc region of $\operatorname{IgG}$ ) were added as negative controls.

Activated PBMCs were prepared according to the following procedure. A concentration of $1 \mu \mathrm{g} / \mathrm{ml} \mathrm{PWM} \mathrm{(lectin} \mathrm{from}$ Phytolacca Americana; Sigma, St. Louis, MO, USA) and PBS, AChR $(30 \mu \mathrm{g} / \mathrm{ml})$, or AChR-Fc $(10,30,100 \mu \mathrm{g} / \mathrm{ml})$ were added to the media. PBMCs were incubated at a temperature of $37^{\circ} \mathrm{C}$ for 4 days, in a 96 -well tissue culture plate at $1 \times 10^{5}$ cells/well $/ 100 \mu \mathrm{l}$.

An enzyme-linked immunospot (ELISPOT) assay was performed according to the following procedure. An AChR solution $(10 \mu \mathrm{g} / \mathrm{ml}$ in PBS) was added to a MultiScreen plate (Millipore) at $100 \mu \mathrm{l} /$ well and placed (stationary) at a temperature of $4{ }^{\circ} \mathrm{C}$ overnight. After washing with PBS and adding $1 \%$ bovine serum albumin/PBS, the samples were blocked at room temperature for $1 \mathrm{~h}$. After washing with PBS, the activated $\mathrm{PBMC}$ suspension was added and incubated at a temperature of $37^{\circ} \mathrm{C}$, in a $\mathrm{CO}_{2}$ incubator, for $4 \mathrm{~h}$. After washing with PBS and $0.1 \%$ Tween/PBS, goat antihuman Ig-AP (SouthernBiotech, Birmingham, AL, USA) was added and the reaction proceeded at a room temperature for $2 \mathrm{~h}$. After washing with $0.1 \%$ Tween/PBS and PBS, the samples were incubated with the developing reagent (nitroblue tetrazolium/ 5-bromo-4-chloro-3-indolyl phosphate). After air-drying, the number of spots was counted by microscopy.

\section{Preparation of AChR}

AChR-Fc $(5 \mathrm{mg} / \mathrm{ml})$ was incubated with papain $(0.1 \mathrm{mg} / \mathrm{ml}$; Sigma), under reducing conditions, at a temperature of $25^{\circ} \mathrm{C}$ for $1.5 \mathrm{~h}$. The reaction was terminated by the addition of iodoacetoamido (0.04 mM; Wako, Richmond, VA, USA). After digestion of papain, the AChR was separated from the $\mathrm{Fc}$ fraction, unreacted $\mathrm{AChR}-\mathrm{Fc}$, papain, and iodoacetoamido by anion exchange column chromatography (Hi-Trap Q; GE Healthcare), and dialyzed against PBS.

\section{Induction and Clinical Evaluation of a Passive Transfer MG Model}

Female Lewis rats were purchased from Japan SLC, Inc. (Shizuoka, Japan). Rats, 11 weeks of age, were intraperitoneally injected with $1.5 \mathrm{mg} / \mathrm{kg} \mathrm{mAb} 35$ in PBS and assessed for changes in clinical score. Animals were scored by following the system of Chamberlain-Banoub et al. [9]. Half scores were given for intermediate signs. AChR-Fc was intravenously administered at a dose of $0.4,2.0$, or $10 \mathrm{mg} / \mathrm{kg}$, at $4,12,24$, and $32 \mathrm{~h}$ after mAb35 administration. The same volume of PBS was intravenously administered to the control group.

\section{Induction and Clinical Evaluation of Active Immunization MG Model}

Torpedo AChR (TA) was purified from the electroplax tissue of Torpedo californica by affinity chromatography using a slightly modified method described previously [10]. For serum antibody detection, we used a recombinant $\alpha$ subunit of TA $($ rTA $\alpha)$. We artificially synthesized a gene sequence corresponding to the extracellular domain of TA $\alpha 1$ subunit (TA $\alpha 1-210$, Swiss-Prot ID: P02710). A recombinant expression plasmid incorporating the above sequence was constructed and expressed using Escherichia coli BL21 (DE3).

Female Lewis rats, 8 weeks of age, were immunized once, in both hind footpads, by subcutaneous injection of TA $(50 \mu \mathrm{g} / \mathrm{rat}$ in $200 \mu \mathrm{l})$ emulsified in complete Freund adjuvant and additionally containing $0.4 \mathrm{mg} / \mathrm{rat}$ Mycobacterium tuberculosis (Difco, Leeuwarden, the Netherlands) [11]. Clinical severity in animals was scored by following the method of Zhu et al. [11]. AChR-Fc was administrated by intravenous injection at a dose of 5,10 , or $20 \mathrm{mg} / \mathrm{kg} /$ day. Each course of treatment was composed of 5 consecutive daily injections 
and started at 7, 21, and 35 days after immunization. Eight weeks after TA immunization, rat serum was collected from the tail vein for detection of rTA $\alpha$-specific IgG by the ELISA. Microtiter plates were coated with $\mathrm{rTA} \alpha$ and incubated with the tested rat serum. Total bound IgG was detected using horseradish peroxidase-conjugated goat antirat IgG (Bethyl, Montgomery, TX, USA), followed by measurement of peroxidase activity assessed at $450 \mathrm{~nm}$. Eight weeks after TA immunization, blood sampling was not available for some rats because of severe generalized weakness or death. Therefore, we evaluated the IgG titer of $8,4,4,7$, and 7 serum samples from normal, control, AChR-Fc $5 \mathrm{mg} / \mathrm{kg}$, AChR-Fc $10 \mathrm{mg} / \mathrm{kg}$, and AChR-Fc $20 \mathrm{mg} / \mathrm{kg}$ groups, respectively ( 8 rats per group at initiation of treatment).

\section{Statistical Analysis}

In animal studies, for analysis of differences between the AChR-Fc groups and the control group, we performed a parametric or nonparametric Dunnett's test after verifying the homogeneity of variance using Bartlett's test. Statistical significance was defined as $p<0.05$. Statistical analysis was performed using the SAS preclinical package (SAS Institute Inc., Cary, NC, USA).

\section{Results}

\section{AChR-Fc Binds to Anti-AChR Antibody}

The binding of AChR-Fc to antiacetylcholine receptor antibodies was evaluated according to the following procedure. First, binding to $\mathrm{mAb} 35$ was measured by the surface plasmon resonance method (Fig. 1A). Herein, concentration-dependent binding was observed. The calculated dissociation constant was $9.95 \mathrm{nM}$. Subsequently, the binding to the IgG fraction obtained from blood samples of patients with MG was confirmed by ELISA (Fig. 1B). In this experiment, specific binding of AChR-Fc to the IgG fraction purified from patients' blood was observed. In addition, the binding of AChR-Fc to patients' IgG fraction was observed in the samples of all 16 patients in this study (Table 1).

\section{AChR-Fc has Cytotoxicity Against Hybridoma Cells Producing anti-AChR Antibody}

The binding of AChR-Fc to TIB-175 was evaluated using anti-AChR antibody mAb35-producing TIB-175 cells (Fig. 2A). Cellular cytotoxicity of AChR-Fc mediated by effector cells was also confirmed (Fig. 2B). First, the binding capacity of AChR-Fc to TIB-175 cells was evaluated by flow cytometry, which indicated binding of AChR-Fc to TIB-175. It was also shown that binding was specific to anti-AChR antibody-producing cells, as AChR-Fc did not bind irrelevant hybridoma cells (data not shown). Subsequently, the cellular cytotoxicity to TIB-175 cells was measured. The measurement of cellular cytotoxicity was performed by adding NK92 (used as effector cells) to TIB-175 cells. The results showed that AChR-Fc had cellular cytotoxicity to TIB175 cells in a dose-dependent manner. In addition, etanercept, which has a structure similar to that of AChR-Fc, had no cellular cytotoxicity to TIB-175 cells, suggesting that the cytotoxicity was specific to the AChR subunit of the AChR-Fc.

\section{AChR-Fc has Cytotoxicity Against Patient PBMC-Derived Autoantibody-Producing B Cells}

Using the PBMC fraction prepared from patients with MG, cellular cytotoxicity to autoantibody-producing B cells was evaluated by ELISPOT assay (Fig. 3). In the PBS group (without antigen stimulation), spots were observed only in some patient samples with mature B cells in the blood. In the AChR group (with antigen stimulation), spots were observed in all patient samples. In the AChR-Fc group (with antigen stimulation and cellular cytotoxicity), spots were observed only in few patient samples. The fact that few spots were observed, despite antigen stimulation, suggested that mature B cells (related to autoantibody production) or memory B cells in the blood of patients with MG were impaired. In contrast, when PBMCs from healthy individuals were used, no spots were observed in the PBS, AChR-Fc, or AChR groups.

\section{AChR-Fc Suppressed Clinical Severity in a Passive Transfer MG Model}

Signs of muscle weakness were initiated $24 \mathrm{~h}$ after injection of the inducing antibody (mAb35) and were most severe at $56 \mathrm{~h}$. AChR-Fc suppressed this increase in clinical score in a dose-dependent manner. In addition, the development of signs was delayed in the AChR-Fc $10 \mathrm{mg} / \mathrm{kg}$ administered group and MG scores were significantly lower in this group compared with those of the control group at $32 \mathrm{~h}$ or later (Fig. 4).

\section{AChR-Fc Suppressed Clinical Severity in an Active Immunization MG Model}

The effectiveness of AChR-Fc in treating clinical signs (Fig. 5A) and the rTA $\alpha$-specific IgG titer (Fig. 5B) was evaluated in rats. Transient signs, due to excessive immune response, were observed in all groups approximately 2 weeks after TA immunization. In the control group, the clinical score increased markedly 4 weeks after TA immunization. In the AChR-Fc administered groups, a suppressive effect and 
a

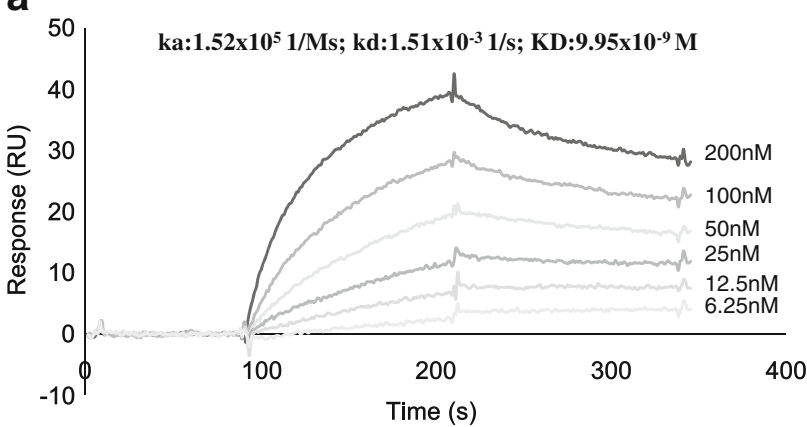

b

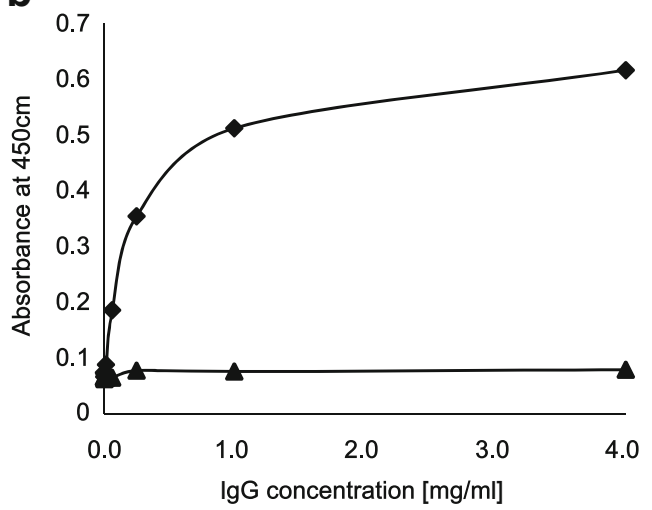

Fig. 1 Binding of the acetylcholine receptor (AChR)-Fc fusion protein to antiacetylcholine antibody receptor. (A) Surface plasmon resonancekinetic analysis of AChR-Fc binding to mAb35. AChR-Fc was immobilized on a sensor chip and reacted with 6.25 to $200 \mathrm{nM}$ of $\mathrm{mAb} 35$ at a temperature of $25{ }^{\circ} \mathrm{C}$ in $20 \mu \mathrm{l} / \mathrm{ml}$ solution. (B) Enzyme-

delayed onset of signs were observed in a dose-dependent manner. This effect was significant for AChR-Fc treatment at both 10 and $20 \mathrm{mg} / \mathrm{kg}$, at 5 weeks or later. In addition, serum anti-rTA $\alpha \operatorname{IgG}$ levels were measured. From total $\mathrm{IgG}$, induced by antigen immunization, $\operatorname{IgG}$ against the $\alpha$ subunit was detected and the levels were measured. The level of anti-rTA $\alpha$ IgG detected in the serum after antigen immunization was significantly lower in the AChR-Fc administered group. Eight weeks after immunization, we collected serum samples from tail veins and detected anti-rTA $\alpha$ IgG. AChR-Fc suppressed the increase of anti-rTA $\alpha$ IgG and the level of IgG was significantly lower than that of the control. linked immunosorbent analysis of the interaction between patient IgG and AChR-Fc. The IgG fraction purified from blood [patient $(\bullet)$ or control $(\boldsymbol{\Delta})$ ] was immobilized at a concentration ranging from $0.24 \mu \mathrm{g} / \mathrm{ml}$ to $4.0 \mathrm{mg} / \mathrm{ml}$, and subsequently reacted with AChR-Fc. $\mathrm{RU}=$ relative units

\section{Discussion}

$\mathrm{AChR}$, found at the neuromuscular junction, is a pentamer of $2 \alpha 1, \beta, \gamma$, and $\delta$ subunits in the fetus and newborn. After that, the $\gamma$ subunit changes to an $\varepsilon$ subunit. The binding site of AChR is within the $2 \alpha 1$ subunits of the pentameric complex. The binding of ACh to the receptor leads to opening of ion channels, which allows $\mathrm{Na}^{+}$to flow into the muscle, leading to increased concentrations of $\mathrm{Ca}^{2+}$ in the muscle, and triggering muscle contraction. Tzartos et al. [12] reported that the many $\mathrm{AChR}$ antibodies bind to a region of the receptor $\alpha$ subunit, called the main immunogenic region. From these findings, we considered that inhibition of antibodies to the AChR $\alpha$ subunit
Table 1 Patient characteristics and reactivity to acetylcholine receptor (AChR)-Fc

\begin{tabular}{llllll}
\hline & Reactivity to AChR-Fc & Autoantibody titer & MGFA clinical classification & Age (y) & Sex \\
\hline MG01 & + & 630 & Ila & 23 & M \\
MG02 & + & 39 & IIa & 68 & F \\
MG03 & + & 45 & Ilb & 30 & F \\
MG04 & + & 12 & I & 54 & M \\
MG05 & + & 160 & IIa & 25 & F \\
MG06 & + & 37 & I & 77 & F \\
MG07 & + & 5.3 & 0 & 75 & M \\
MG08 & + & 19 & IIa & 46 & F \\
MG09 & + & 5.7 & I & 71 & F \\
MG10 & + & IIIb & 71 & M \\
MG11 & + & 25 & IIa & 64 & M \\
MG12 & + & 4.8 & I & 50 & F \\
MG13 & + & 8.1 & IIIa & 66 & F \\
MG14 & + & 3.3 & IIIa & 86 & F \\
MG15 & + & 1.0 & IIa & 81 & F \\
MG16 & + & 9.4 & V & 62 & M \\
\hline
\end{tabular}

MGFA = Myasthenia Gravis Foundation of America; $\mathrm{M}=$ male $; \mathrm{F}=$ female 
a

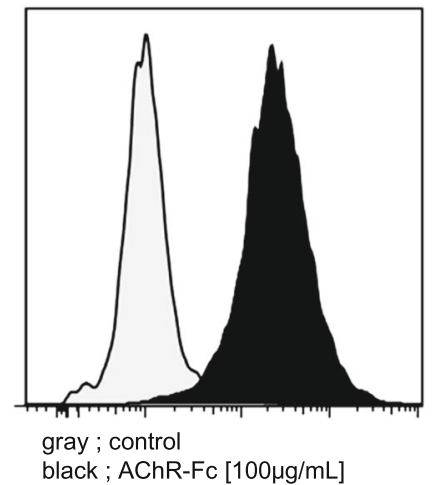

Fig. 2 Confirmation of binding to TIB-175 cells and cellular cytotoxicity. (A) The binding to TIB-175 cells was confirmed using a flow cytometer. Gray $=$ control; black $=$ acetylcholine receptor $(\mathrm{AChR})$ Fc administration (100 $\mu \mathrm{g} / \mathrm{ml})$. (B) Cellular cytotoxicity to TIB-175 cells

may be an effective treatment for patients with MG. In the present study, we created AChR-Fc, and examined its effects on autoantibody production and autoantibodyproducing cells.

First, we examined the neutralization activity of the AChRFc. This protein bound to $\mathrm{mAb} 35$ in a concentration-

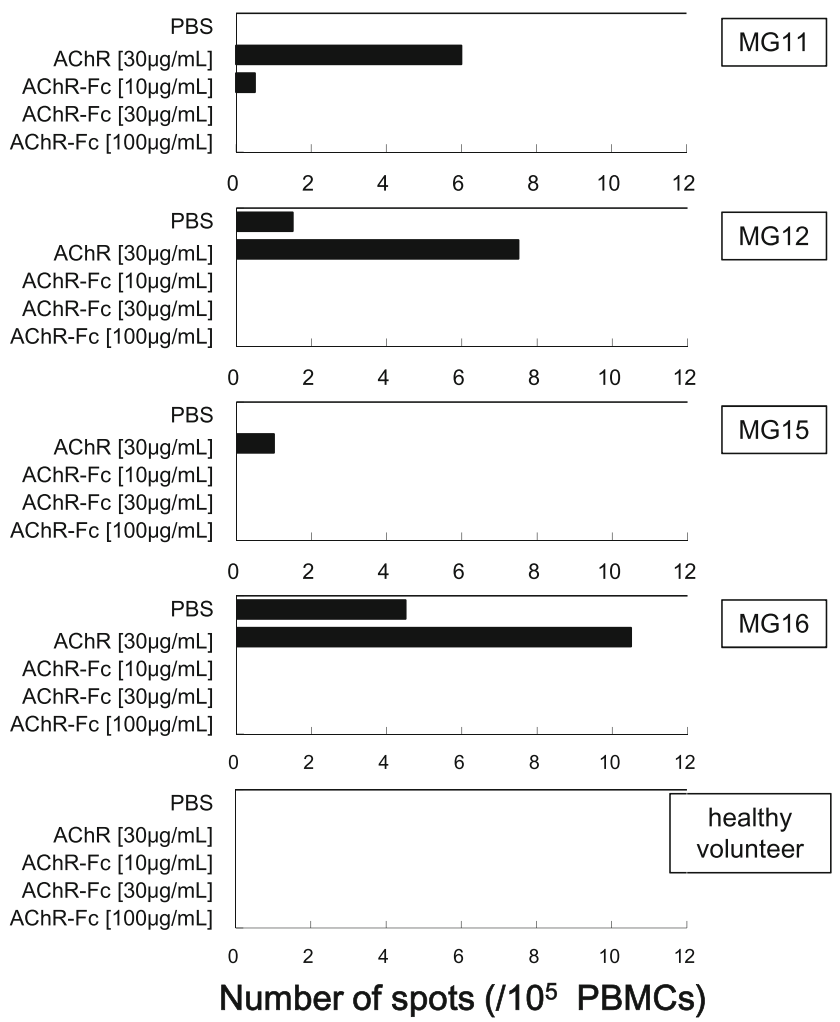

Fig. 3 Confirmation of cellular cytotoxicity to clinical samples [enzymelinked immunospot (ELISPOT) assay]. Acetylcholine receptor (AChR) protein was immobilized on an ELISPOT plate (on a polyvinylidene fluoride membrane). PBS = phosphate buffered saline; $\mathrm{PBMC}=$ peripheral blood mononuclear cell

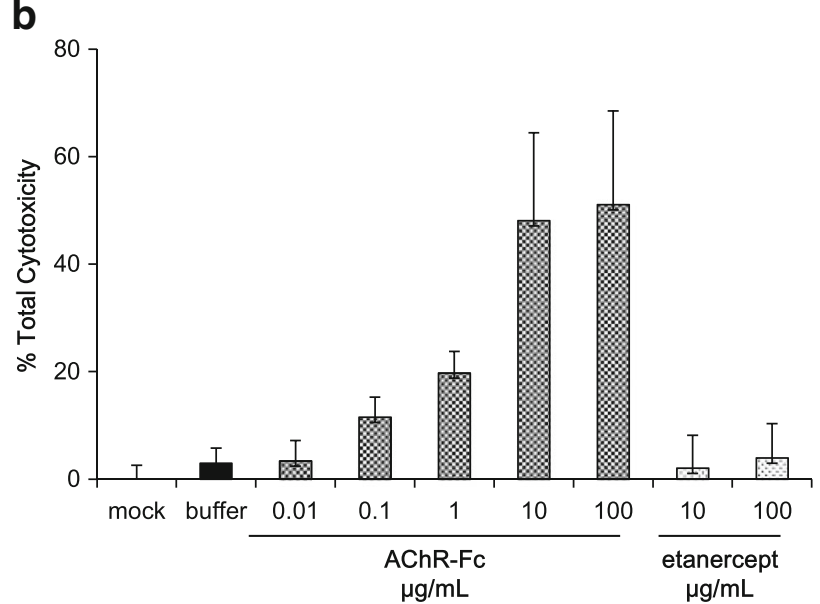

was confirmed. TIB-175 cells were treated with Calcein-AM and incubated with NK92 cells. AChR-Fc $(0.01,0.1,1,10,100 \mu \mathrm{g} / \mathrm{ml})$ or etanercept $(10,100 \mu \mathrm{g} / \mathrm{ml})$ was then added. Mean and SD are indicated.

dependent manner. The dissociation constant was approximately $10^{-8} \mathrm{M}$, which is considered to be within the general range for that of antigen-antibody reactions. Neutralization activity was observed not only to $\mathrm{mAb35}$, but also to patient-derived antibodies. Among the subunits of AChR, only the AChR-Fc has an $\alpha 1$ subunit extracellular domain. The binding between AChR-Fc and patients' antibodies was found in all 16 patients, suggesting that all patients in this study had anti-AChR antibodies specific to the $\alpha 1$ subunit.

Subsequently, we examined the cytotoxicity of AChR-Fc and discovered binding of AChR-Fc to TIB-175 cells, and cytotoxicity to patient-derived PBMCs. We considered the

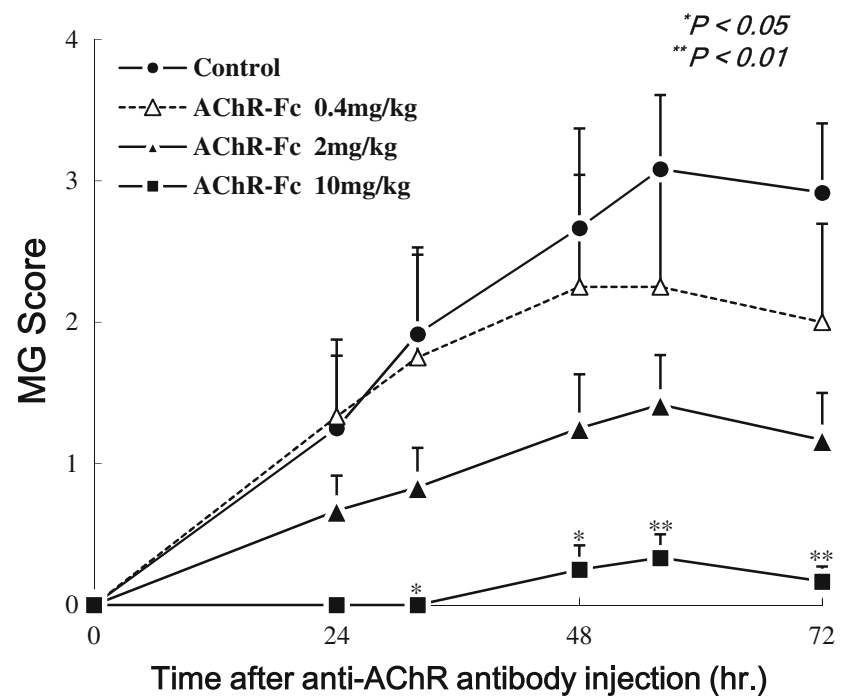

Fig. 4 Effectiveness of acetylcholine receptor (AChR)-Fc in a passive transfer myasthenia gravis (MG) model. Mean MG score of rats (6 in each group) administered an anti-AChR antibody $(\mathrm{mAb} 35)$ and treated with AChR-Fc. Rats were treated 4 times with AChR-Fc $(0.4,2,10 \mathrm{mg} / \mathrm{kg})$. Mean and SEM are indicated. $* p<0.05$ and $* * p<0.01$ compared with the control group 
a

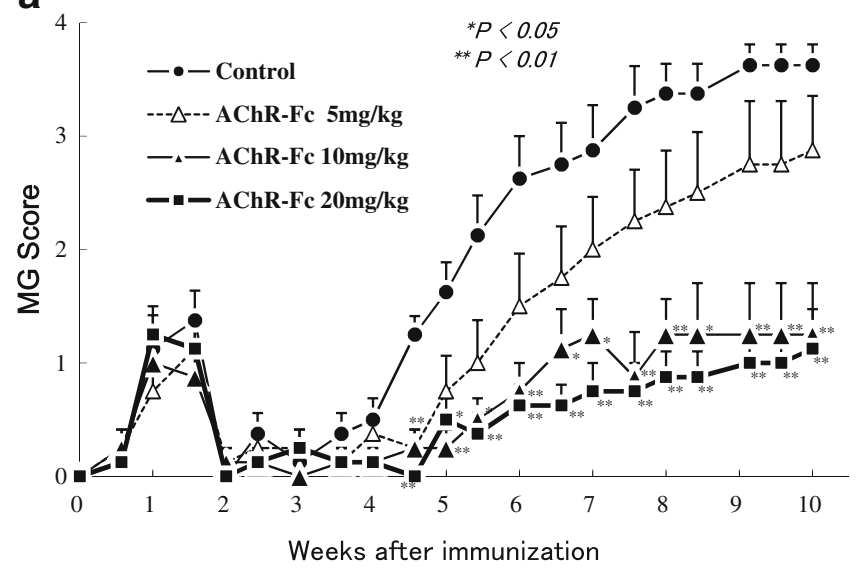

b

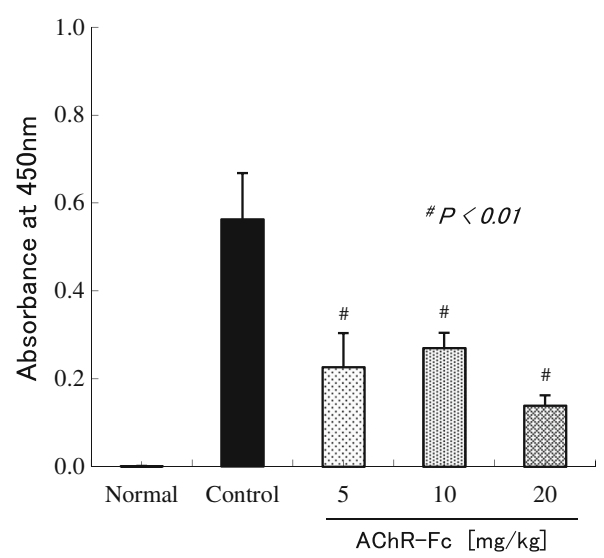

Fig. 5 Effectiveness of acetylcholine receptor (AChR)-Fc in an active immunization myasthenia gravis (MG) model. (A) Mean score of rats $(8$ in each group) immunized with Torpedo AChR (TA) and treated with AChR-Fc. Rats were treated with 3 different courses of AChR-Fc $(5,10$, $20 \mathrm{mg} / \mathrm{kg} /$ day) starting 7 days after immunization. Mean and SEM are indicated. $* p<0.05$ and $* * p<0.01$ compared with the control group. (B)

mechanism of cytotoxicity as follows. The binding of AChRFc $\alpha 1$ to the anti-AChR receptor antibodies, and the binding of the Fc region to effector cells, promotes antibodydependent cellular cytotoxicity against specific B cells. To confirm this hypothesis, we conducted an experiment examining cytotoxicity in TIB-175 cells. These cells, like antibodyproducing B cells, express antibodies on the cell surface; here, concentration-dependent cytotoxicity was confirmed in vitro. In contrast, cytotoxicity was not observed with etanercept, suggesting that the response was specific to $\mathrm{AChR} \alpha 1$. We also examined the cytotoxicity of AChR-Fc to patient-derived autoantibody-producing cells using ELISPOT. Patient-derived PMBCs were obtained from 4 patients. Without AChR stimulation, autoantibody-producing cells were observed in 2 patients. With AChR stimulation, autoantibody-producing cells were observed in 4 patients. However, the number of these cells was reduced by AChR-Fc administration. After administration of $30 \mu \mathrm{g} / \mathrm{ml} \mathrm{AChR,} \mathrm{no} \mathrm{autoantibody-producing} \mathrm{cells}$ were observed. These results suggested that administration of AChR-Fc affected AChR antigen stimulation and caused cellular cytotoxicity.

Based on these results, we examined the effectiveness of AChR-Fc using a rat passive induction MG model. Herein, a dose-dependent suppression of clinical signs after AChR-Fc administration was observed, suggesting that the AChR-Fc neutralized autoantibodies in rats, leading to alleviation of the disease. In the active induction model, we tested autoantibody neutralizing activity and cellular cytotoxicity. Here, a dose-dependent suppression of clinical signs was observed. In addition, anti-AChR antibody levels showed a tendency to decrease. However, the underlying mechanism of this effect remains to be elucidated. The observed reduction in autoantibody levels might be the result of the neutralizing activity of
rTA $\alpha$-specific IgG titer in rat serum. The antibody levels were measured in blood samples obtained 8 weeks after TA immunization. After immobilizing rTA $\alpha$, and incubating with serum, the antibody levels were detected using an horseradish peroxidase-labeled antirat IgG antibody. Mean and SEM are indicated. ${ }^{\#} p<0.01$ compared with the control group

AChR-Fc. There is also a possibility that this reduction in antibody levels was caused by cytotoxicity to antibodyproducing B cells. Further studies are required to clarify the underlying mechanism.

A previous study [7] has reported the effect of AChR-Fc in vitro, using TIB-175 cells that produce anti-AChR antibodies. In this report, AChR-Fc binds to anti-AChR antibodies produced by TIB-175 cells expressing B-cell receptor and Fc $\gamma$ RIIB (CD32); it also inhibits growth, promotes apoptosis, and causes cytotoxicity in these cells. However, its effects on patients with MG are not clear as TIB-175 cells exhibit monoclonal antibody production, whereas patients' autoantibodies have numerous variations. Therefore, we performed analyses using PBMCs and various antibodies obtained from patients with MG.

In this study, we prepared the peptide such that the constant region of human IgG1 was downstream of the human $\alpha 1$ $\mathrm{AChR}$ region; these regions were conjugated by a $\mathrm{P}(\mathrm{GGGGS})_{3}$ linker. This AChR-Fc construct is different than that of the previous report. Our construct also had binding and cytotoxic activity towards TIB-175 cells, and we could also demonstrate reactions against IgG and B cells from patients with MG. Moreover, it has been confirmed that AChR-Fc, specifically, has cytotoxic activity towards anti-AChR antibody-producing B cells. From these results, AChR-Fc is expected to be effective in the treatment of MG.

It is speculated that AChR-Fc attacks and eliminates autoantibody-producing B cells; therefore, its effects are likely to be long-term. Although the administration with periodical $\mathrm{AChR}-\mathrm{Fc}$ is required, treatment with AChR-Fc could have longer-lasting effects compared with those of conventional treatment such as cholinesterase-inhibitors and high-dose intravenous immunoglobulin. In addition, the immune 
suppressive activity of AChR-Fc is expected to be specific to autoantibody-producing B cells, which is different from conventional immunosuppressants that suppress the entire immune system. Recently, anti-C5 antibody therapy and antiCD20 antibody therapy have been developed and were shown to be effective $[13,14]$. However, these drugs might suppress the immune system in a nonspecific manner. In contrast, AChR-Fc may be a promising drug as a specific anti-AChR antibody inhibitor.

Anti-AChR antibody-producing B cells bind to AChR region of fusion protein. Although our results showed AChR-Fc specifically killed the autoantibody-producing B cells by antibody-dependent cellular cytotoxicity, the possibility that the binding of B cells and AChR-Fc may stimulate the B cells and anti-AChR antibody production cannot be denied.

In conclusion, the results of the present study suggest that the AChR-Fc may improve the symptoms of anti-AChR antibody-positive patients with MG by neutralization of autoantibodies and cytotoxicity to autoantibody-producing B cells. Further study in patients with MG will be needed to address this issue.

Required Author Forms Disclosure forms provided by the authors are available with the online version of this article.

\section{References}

1. Lindstrom JM, Seybold ME, Lennon VA, et al. Antibody to acetylcholine receptor in myasthenia gravis. Prevalence, clinical correlates, and diagnostic value. Neurology 1976;26:1054-1059.

2. Hoch W, McConville J, Helms S, et al. Auto-antibodies to the receptor tyrosine kinase MuSK in patients with myasthenia gravis without acetylcholine receptor antibodies. Nat Med 2001;7:365-368.
3. Higuchi O, Hamuro J, Motomura M, et al. Autoantibodies to lowdensity lipoprotein receptor-related protein 4 in myasthenia gravis. Ann Neurol 2011;69:418-422.

4. Leite MI, Jacob S, Viegas S, et al. IgG1 antibodies to acetylcholine receptors in 'seronegative' myasthenia gravis. Brain 2008;31:19401952.

5. Meyer A, Levy Y. Geoepidemiology of myasthenia gravis [corrected]. Autoimmun Rev 2010;9:A383-A386.

6. Conti-Fine BM, Milani M, Kaminski HJ. Myasthenia gravis: past, present, and future. J Clin Invest 2006;116:2843-2854.

7. Chang T, Lin H, Gao J, et al. Selective recognition and elimination of nicotinic acetylcholine receptor-reactive B cells by a recombinant fusion protein AChR-Fc in myasthenia gravis in vitro. $\mathrm{J}$ Neuroimmunol 2010;227:35-43.

8. Jaretzki A 3rd, Barohn RJ, Ernstoff RM, et al. Myasthenia gravis: recommendations for clinical research standards. Task Force of the Medical Scientific Advisory Board of the Myasthenia Gravis Foundation of America. Neurology 2000;55:16-23.

9. Chamberlain-Banoub J, Neal JW, Mizuno M, et al. Complement membrane attack is required for endplate damage and clinical disease in passive experimental myasthenia gravis in Lewis rats. Clin Exp Immunol 2006;146:278-286.

10. Tomino H. The effect of thymectomy and splenectomy on experimental myasthenia gravis. J Nagoya City Univ Med Assoc 1994;45:81-98.

11. Zhu KY, Feferman T, Maiti PK, et al. Intravenous immunoglobulin suppresses experimental myasthenia gravis: immunological mechanisms. J Neuroimmunol 2006;176:187-197.

12. Tzartos SJ, Kokla A, Walgrave SL, et al. Localization of the main immunogenic region of human muscle acetylcholine receptor to residues 67-76 of the alpha subunit. Proc Natl Acad Sci U S A 1988;85:2899-2903.

13. Howard JF Jr, Barohn RJ, Cutter GR, et al. A randomized, doubleblind, placebo-controlled phase II study of eculizumab in patients with refractory generalized myasthenia gravis. Muscle Nerve 2013;48:76-84.

14. Iorio R, Damato V, Alboini PE, et al. Efficacy and safety of rituximab for myasthenia gravis: a systematic review and meta-analysis. J Neurol 2015;262:1115-1119. 